\title{
Recruitment Period
}

National Cancer Institute

\section{Source}

National Cancer Institute. Recruitment Period. NCI Thesaurus. Code C142664.

The interval of time during which subjects are to be enrolled in a clinical study. 